\title{
Ensino do modelo atômico de Bohr, quimioluminescência e luminol: análise dos livros didáticos de Campo Mourão com base nas diretrizes curriculares da educação básica de química do Paraná
}

Adil de Souza Oliveira Junior adiljunior@alunos.utfpr.edu.br Paraná - UTFPR, Campo Mourão, Paraná, Brasil

\section{Maria Vitória de Oliveira}

\section{Rodrigues}

mvitoriadeoliveira1@gmail.com Universidade Tecnológica Federal do Paraná - UTFPR, Campo Mourão, Paraná, Brasil

Lorena Gabriela da Silva Ovídio Pereira

lorenaovidiopereira@gmail.com Universidade Tecnológica Federal do Paraná - UTFPR, Campo Mourão, Paraná, Brasil

\section{Bruna Adriane Fary}

fary.bruna@gmail.com

Paraná - UTFPR, Campo Mourão,

Paraná, Brasil

\section{RESUMO}

O artigo sugere a contextualização do ensino do postulado de Bohr com o cotidiano social, usando o conceito de quimioluminescência a partir da química forense, com o objetivo de instigar o interesse e o senso crítico do aluno, mostrando uma aplicação prática da reação química do luminol. O estudo se realizou por meio da leitura e análise de três livros didáticos de química do primeiro ano do ensino médio, utilizados no Município de Campo Mourão, comparando-os com as Diretrizes Curriculares da Educação Básica de Química do Estado do Paraná (DCE). Foram analisados os livros Química Cidadã de Wildson Santos e Gerson Mól, Química de Ricardo Feltre e Química de Martha Reis, que apresentaram algumas distinções a partir dos critérios estabelecidos. Além disso, foi proposta uma atividade prática para uma melhor contextualização com o cotidiano dos alunos. Ao término da pesquisa foi observado que o modelo atômico de Bohr possui algumas carências nos livros didáticos analisados. Além disso, por apresentarem pouca contextualização, vai contra o que as DCE defendem.

PALAVRAS-CHAVE: Livros didáticos. Modelo atômico. Quimioluminescência. Química forense. 


\section{INTRODUÇÃO}

A elaboração deste trabalho teve como ponto de partida discussões em grupo, durante as aulas da disciplina de Metodologia da Pesquisa em Educação, do curso de Licenciatura em Química da Universidade Tecnológica Federal do Paraná, onde tentamos aliar o ensino de química com a química forense. Diante de tantas informações disponíveis sobre tal temática, como seriados, filmes, desenhos e livros, tentamos utilizar a química forense como uma ferramenta pedagógica, visando facilitar a integração do aluno com os meios de comunicação e associar os conceitos químicos com a linguagem e conhecimentos que o mesmo já possui.

Nas Orientações Curriculares Para o Ensino Médio (2006), há uma normativa onde prega a necessidade de abordar temas sociais, do cotidiano, dentro do ensino de química, aliando a experimentação com a teoria, como meio de motivar o educando. A partir desse pensamento, é imprescindível reforçar as metodologias de ensino, de acordo com as orientações curriculares, buscando suprir as fragilidades do ensino atual, aproximando assim o conhecimento ao aluno. A química é uma ciência que pode fornecer explicações para tudo que está presente em nossa volta, e também apresenta grande influência na vida dos cidadãos, portanto, conhecer e entender os conceitos químicos é útil para participar criticamente dos contextos da sociedade atual (ALMEIDA et al, 2007).

A educação é a ferramenta de transformação social e política de grande importância, e cabe ao professor utilizar-se de metodologias e analises para contextualizar suas aulas e também influenciar as vidas que pulsam em sala de aula. Trazer o cotidiano correlacionando-o com a teoria, pode fazer com que o educando tenha uma aprendizagem mais efetiva e integrada. Todavia, é preciso garantir essa contextualização de uma forma que desperte a curiosidade e atenção do discente.

Muitas das vezes, o ensino se torna maçante, para o aluno e também para o professor, as aulas se tornam repetitivas, com conteúdo muito teórico, que acaba não deixando lacunas para o docente introduzir práticas e contextualizar o ensino. Quando não há uma contextualização adequada, o ensino se torna algo abstrato e distante do aluno, como afirmado por Zanon e Palharini (1995).

"Reduz-se o conhecimento químico a fórmulas matemáticas e à aplicação de "regrinhas", que devem ser exaustivamente treinadas, supondo a mecanização e não o entendimento de uma situação-problema" (BRASIL, 1999). A metodologia utilizada nas escolas brasileiras é baseada no ensino macetes, resumos, fórmulas, esquemas, entre outras formas de estudo, com a finalidade de induzir o aluno a memorizar o conteúdo, ao invés de realmente aprender, com isso seu rendimento escolar decresce e automaticamente a atração pela disciplina também.

Os Parâmetros Curriculares Nacionais do Ensino Médio (PCNEM), foram elaborados para auxiliar os professores na elaboração de suas aulas, tendo uma fala direta para com o docente, abrangendo todos os âmbitos e dificuldades escolares. Porém, os PCNEM não são obrigatórios, cada Estado pode ter os seus próprios parâmetros. No Estado do Paraná o documento que rege tais práticas são as Diretrizes Curriculares Estaduais - DCE (PARANÁ, 2008).

As DCE (PARANÁ, 2008) de química trazem uma metodologia inovadora, em que defendem um ensino contextualizado, e uma integração entre as disciplinas, 
para que o educando possa aprender mais que o conteúdo, e consiga relacionar os conhecimentos com fluidez. "Textos de Literatura e Arte podem se tornar ótimos instrumentos de abordagens interdisciplinares no ensino de Química" (PARANÁ, 2008). Agregar cultura com o ensino de química é um grande passo para uma interdisciplinaridade dos conteúdos, e pode integrar o aluno em um contexto onde o conhecimento é absorvido com mais facilidade.

Mesmo tendo a orientação de seguir as DCE, o docente tem a liberdade de escolher e organizar seu cronograma de aulas, porém, na hora de efetuar tais ações, é necessário levar em conta o perfil dos discentes e também dominar o conteúdo a ser explicado. Para Piletti (2004) a seleção dos conteúdos deve ser baseada nos seguintes critérios:

Validade: Haver uma relação clara e nítida entre os objetivos a serem atingidos com o ensino e os conteúdos trabalhados. Isto quer dizer que os conteúdos devem estar adequados e vinculados aos objetivos estabelecidos para o processo de ensino e aprendizagem.

Utilidade: 0 critério de utilidade está presente quando há possibilidade de aplicar o conhecimento adquirido em situações novas. Os conteúdos curriculares são considerados úteis quando estão adequados às exigências e condições do meio em que os alunos vivem, satisfazendo suas necessidades e expectativas e, quando têm valor prático para eles, ajudando-os na vida cotidiana a solucionar seus problemas e a enfrentar as situações novas.

Significação: Um conteúdo será significativo e interessante para o aluno quando estiver relacionado às experiências por ele vivenciadas. Por isso, o professor deve procurar relacionar, sempre que possível os novos conhecimentos a serem adquiridos pelos alunos, com suas experiências e conhecimentos anteriores, fazendo uma ponte para ligar o já conhecido ao novo e ao desconhecido. É esta ligação do conhecido e vivenciado ao desconhecido e novo que torna o conteúdo significativo e interessante.

Adequação ao nível de desenvolvimento do aluno: $O$ conteúdo selecionado deve respeitar o grau de maturidade e intelectual do aluno e estar adequado ao nível de suas estruturas cognitivas. Os conteúdos a serem assimilados devem corresponder às aprendizagens essenciais e desejáveis, contribuindo para o desenvolvimento das potencialidades do aluno, de acordo com sua fase evolutiva e com os interesses que o impelem a ação.

Flexibilidade: O critério de flexibilidade estará sendo atendido quando houver possibilidade de fazer alterações nos conteúdos selecionados suprimindo itens ou acrescentando novos tópicos, a fim de ajustá-los ou adaptá-los às reais condições, necessidades e interesses do grupo de alunos. (PILETTI, 2014, p. 92).

Tendo em mente esses critérios, o presente trabalho se propõe a analisar os livros didáticos no município de Campo Mourão, a fim de observar como é tratado o ensino do modelo atômico de Bohr e utilizar como complementação e exemplificação a quimioluminescência, química forense e a reação química do luminol. O modelo atômico de Bohr foi escolhido para ser trabalhado por ser um dos primeiros conteúdos abordados no primeiro ano do ensino médio, e também por se apresentar como base para o entendimento dos conteúdos subsequentes. Dentre os outros modelos vistos nos livros didáticos, o de Bohr é o que apresenta maior deficiência metodológica, devido a isso, notou-se a necessidade de discutir 
e complementar o ensino deste assunto, aliando-o ao estudo da química forense, com o conteúdo de quimioluminescência.

\section{QUIMIOLUMINESCÊNCIA}

A quimioluminescência é um processo químico que resulta em uma reação luminosa, Nery e Baader (2001) definem tal processo da seguinte forma: "O processo químico da quimioluminescência envolve a absorção, pelos reagentes, de energia suficiente para geração de um complexo ativado, o qual se transforma em um produto eletronicamente excitado" (NERY; BAADER, 2001 p.626). Quando um elétron em estado excitado passa para o estado fundamental, emite Fótons, ou seja, partículas de luz, como retratado na Figura 1.

Figura 1: Movimento entre níveis eletrônicos.

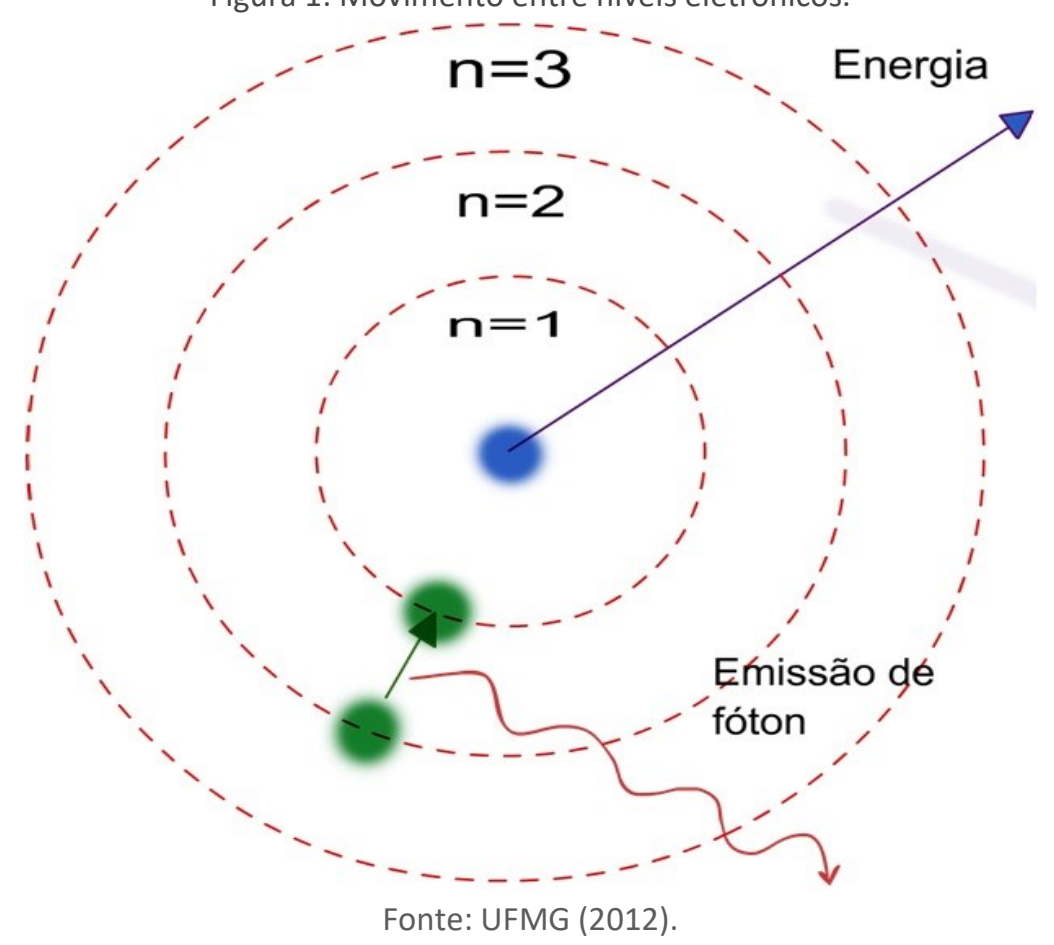

O fenômeno da quimioluminescência é estudado há tempos, desde a antiguidade. Niels Bohr (1885-1962), físico dinamarquês, estabeleceu a primeira conexão das ideias quânticas sobre átomos excitados de Planck e Einstein (KOTZ et al., 2009, p.267). Bohr definiu o átomo como um núcleo carregado de carga positiva, e cercado por uma eletrosfera dividida em níveis de energia, onde estão presentes os elétrons, com carga negativa.

John Kotz et al. (2009), traz a definição estabelecida por Bohr sobre o estado fundamental e o estado excitado do elétron, utilizando como exemplo o hidrogênio: possíveis encontra-se em seu estado fundamental. Quando o elétron de um átomo de hidrogênio ocupa uma orbita com $n$ maior do que 1 , o elétron está mais distante do núcleo o valor de sua energia é menos negativo e então dizemos que ele está em estado excitado. (KOTZ et al., 2009, p.268) 
Essas constatações feitas por Bohr são de grande importância até os dias de hoje, as definições estabelecidas pela observação e experimentação com o átomo de hidrogênio foi uma inovação para época. $E$ a partir dos conceitos estabelecidos por Niels Bohr derivou-se a explicação de outros grandes estudos, como a quimioluminescência, que é de grande importância nas práticas diárias dos químicos forenses e nas perícias criminais.

\section{A QUÍMICA FORENSE}

A química forense atua no entendimento judiciário, fornecendo suas explicações a serviço da perícia criminal, trabalhista, industrial, ambiental e doping esportivo (MOTA; DI VITTA, 2012). Principalmente por atuar no ramo criminal, elucidando assassinatos, se tornou alvo de grande curiosidade, sendo responsável pela criação de diversos documentários, programas televisivos e séries de ficção, trazendo conscientização e um foco maior para a química de modo geral.

Farias (2008), traz um conceito sobre a química forense definindo sua aplicação:

Como o próprio nome indica, a química forense é a utilização/aplicação dos conhecimentos da ciência química aos problemas de natureza forense. Uma definição formal possível: É o ramo da química que se ocupa da investigação forense no campo da química especializada, a fim de entender aspectos de interesse judiciário. (FARIAS, 2008, p.15)

Cotidianamente são notificados crimes brutais, nos quais a grande maioria tem como resultante, a morte. Tais crueldades podem ser desvendadas através da química forense, que ocupa um lugar de destaque quando se trata da prestação de serviços para várias esferas sociais. Esses serviços prestados são de extrema importância, pois além de incriminar culpados, livrando a população da exposição ao perigo causado por criminosos, também absolve inocentes, realizando justiça para todos.

Para que a justiça seja feita, detalhes quase imperceptíveis são de total relevância na perícia criminal, como vestígios de pólvora, rastros de sangue, pegadas e restos de drogas, pois é a partir dessas minúcias que é descoberto todo o decorrer dos fatos, desde a chegada do transgressor no local, o tipo de objeto que o mesmo usou para efetuar o delito, a intenção de realizar tal ação e a forma como deixou a cena do crime. A partir dessas informações são feitas todas as análises, chegando, por fim, no esclarecimento necessário.

Podemos perceber pelos crimes que ocorrem em nossa sociedade que as cenas deixadas pelos criminosos são diversas, Castro e Júnior (2013), apresentam uma breve constatação de tais crimes.

Os crimes classificados como não transeuntes são aqueles que deixam vestígios assim que praticados, e tais crimes deverão ser submetidos a exames periciais, para que ocorra a elucidação do crime, haja vista que possibilitam a descoberta dos verdadeiros criminosos e o modo pelo qual o delito foi praticado, verificando, assim, qualificadoras para o criminoso. (CASTRO; JÚNIOR, 2013, p.181). 
Dentre as investigações feitas pelos peritos criminais, se encontram a identificação de fluidos biológicos, como urina, saliva, sêmen e manchas de sangue, fazendo a coleta de tais resíduos para a análise. No caso das manchas de sangue é realizado um ensaio químico através do luminol, pois tal substância, quando reage com o ferro, presente no sangue, forma uma espécie de luz azul, mostrando visivelmente a mancha, mesmo que o criminoso tenha tentado limpar a cena do crime.

\section{A REAÇÃO QUIMIOLUMINESCENTE DO LUMINOL}

Durante investigações criminais, o luminol é utilizado para identificar a presença de sangue em cenas de crime (WELSH, 2011). O luminol é composto químico formado por nitrogênio, hidrogênio, oxigênio e carbono $\left(\mathrm{C}_{8} \mathrm{H}_{7} \mathrm{O}_{3} \mathrm{~N}_{3}\right)$. É um sólido cristalino, que é solúvel em solventes orgânicos.

A reação química do luminol, é uma oxidação em meio alcalino por peróxido de hidrogênio $\left(\mathrm{H}_{2} \mathrm{O}_{2}\right)$, e foi a primeira reação quimioluminescente, descrita pelo pioneiro Albrecht (FERREIRA; ROSSI, 2002).

O peróxido de hidrogênio e o luminol são os principais elementos da reação, porém há a necessidade de um agente catalisador, que dentre outras funções, produz uma luz mais forte e acelera o processo. Tal mistura detecta o ferro contido na hemoglobina do sangue, que funciona como o catalisador necessário para a reação (LUMINOL: In: WIKIPÉDIA: a enciclopédia livre. Disponível em: <https://pt.wikipedia.org/wiki/Luminol>. Acesso em: 21 abr. 2017.), conforme mostrado na Figura 2.

Figura 2: Grupo heme da hemoglobina: $\mathrm{O}$ átomo de ferro $(\mathrm{Fe})$ no centro do anel porfirina catalisa a reação do luminol.

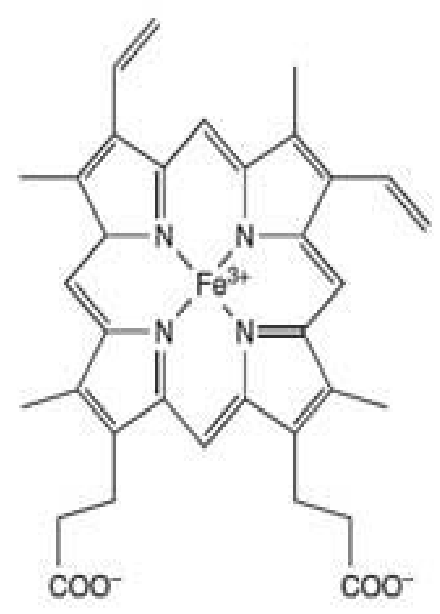

Fonte: Welsh (2011).

O sangue então desempenha o papel de agente catalisador, e não é necessária uma grande quantidade do mesmo para obter um resultado positivo, apenas quantidades residuais já são suficientes, ou seja, o sangue pode ser detectado mesmo não estando detectável a olho nu (WELSH, 2011). 
O ferro é extremamente importante para que se obtenha um bom resultado, e para que a catálise seja desempenhada com sucesso. Uma pessoa adulta pode conter em seu corpo, cerca de 4 a $5 \mathrm{~g}$ de ferro, sendo aproximadamente 2,5 em forma de hemoglobina. "O ferro utilizado pelo organismo é obtido de duas fontes principais: da dieta e da reciclagem de hemácias senescentes" (GROTTO, 2008, p.390).

Durante uma investigação em um local onde ocorreu um crime, um assassinato por exemplo, os investigadores borrifam em qualquer lugar a mistura de peróxido de hidrogênio e luminol, caso haja a hemoglobina do sangue em tal local, o ferro vai atuar como catalisador, e vai acelerar a reação, fazendo com que o luminol perca átomos de nitrogênio e hidrogênio, e ganhe átomos de oxigênio, formando então um composto chamado 3-aminoftalato (LUMINOL: In: WIKIPÉDIA: a enciclopédia livre. Disponível em: <https://pt.wikipedia.org/wiki/Luminol>. Acesso em: 21 abr. 2017.).

Essa reação faz com que o 3-aminoftalato fique em um nível de energia elevado, pois os elétrons dos átomos de oxigênio são levados a um nível superior de energia. E quando tais elétrons retornam a um nível menor, ou como definiu Bohr, ao estado fundamental, há a emissão de fótons. E como há a presença do ferro, a luz emitida é suficiente para ser vista em locais escuros (VIDOTTO; QUEIROZ, 2011), como ilustrado na Figura 3.

Figura 3: Luz emitida na reação química do luminol.

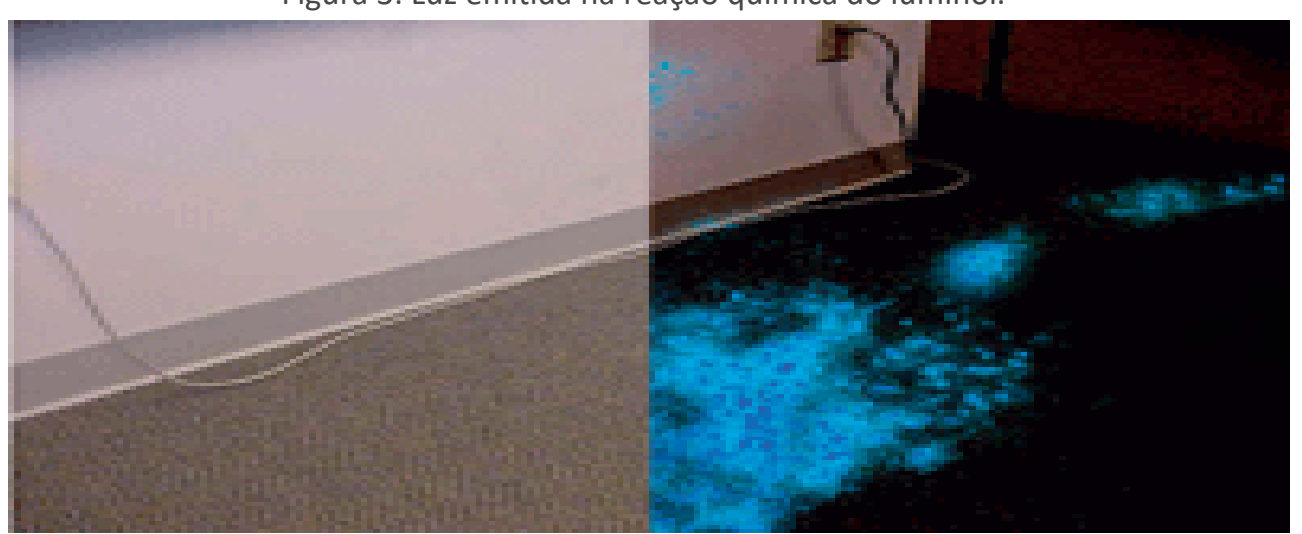

Fonte: Welsh (2011).

A ação do luminol nem sempre é suficiente para resolver um crime, porém o mesmo pode revelar informações que façam com que o processo investigativo evolua. As amostras de sangue que estão invisíveis podem desvendar o ponto de ataque e até mesmo o tipo de arma que foi utilizado (VIDOTTO; QUEIROZ, 2011).

\section{METODOLOGIA}

O presente trabalho tem como foco de interesse, analisar três livros didáticos utilizados em colégios públicos do Município de Campo Mourão e propor uma didática alternativa para o ensino do modelo atômico de Bohr.

Pretende-se avaliar como é abordado o conteúdo programático da teoria atômica de Bohr, a partir de alguns critérios, tais como, conteúdo teórico, atividade prática, exercícios, linguagem utilizada e didática, aproveitando para observar se 
os mesmos estão de acordo com as Diretrizes Curriculares da Educação Básica de Química do Estado do Paraná.

Para reforçar e complementar o ensino do modelo atômico de Niels Bohr, foi proposto aliar a quimioluminescência com o mesmo, e mostrar sua aplicação no cotidiano, durante as investigações criminais. Proporcionado assim, uma melhor aprendizagem, favorecendo ambos os lados, do educador e do educando.

Para realizar a pesquisa e obter os livros para realizar a análise, alguns colégios públicos do Município de Campo Mourão foram consultados. Em 3 deles são utilizados o livro Química Cidadã (2013), dos autores Santos e Mól. E em outros dois colégios utilizam-se livros didáticos distintos, o livro Química (2004) do autor Feltre e o livro Química (2013) da autora Reis.

Após as consultas aos colégios, foi pesquisado o conteúdo de modelos atômicos, visto que é um dos primeiros conteúdos a serem trabalhados no primeiro ano do ensino médio. Chegando no modelo atômico de Bohr, pode-se observar na amarração da metodologia aplicada, algumas falhas e uma contextualização mediana. $\mathrm{O}$ que nos fez refletir em direção a uma abordagem interdisciplinar, para que suprisse as falhas dos livros, fazendo com que assim os mesmos estivessem de acordo com as Diretrizes Curriculares Educacionais do Estado do Paraná (DCE) publicada em 2008.

As DCE (2008) estabelecem que professores podem trabalhar os modelos atômicos, integrando determinadas ocorrências e fenômenos químicos, mostrando assim, a aplicação de tais teorias na prática escolar e do cotidiano. Os docentes podem deixar lacunas para despertar a curiosidade, possibilitando o despertar do ser crítico dos discentes. A ideia é abordar as teorias, relacionandoas as suas funções na ciência, seus objetivos e todo contexto histórico que há em torno da construção da ciência.

Nesse sentido, a química forense nos auxilia a criar elos entre o que o livro didático propõe e o cotidiano, aproximando do aluno os conceitos da química. Assim como defendem as DCE (2008), que apontam como exemplo uma prática realizada por organizações europeias, que traziam fundamentos teóricos aliados ao conhecimento popular e ao cotidiano, tornando a química acessível para toda a sociedade.

\section{RESULTADOS E DISCUSSÃO}

Foram examinados os livros de Wildson Santos e Gerson Mól, Ricardo Feltre e Martha Reis. Embora o livro Química (2004), do autor Ricardo Feltre, não esteja de acordo com o atual PNLD, alguns professores do município de Campo Mourão utilizam o mesmo para a preparação de suas aulas e também como ferramenta de complementação para a aprendizagem dos alunos. Sendo assim, jugou-se necessário a inclusão de tal bibliografia dentro da abordagem do presente artigo.

Em Química Cidadã, volume 1, dos autores Santos e Mól,2013, editora AJS, capitulo 5, tópico 6, a explicação começa pela trajetória dos modelos de Rutherford até Bohr, apresentando os níveis de energia e a transição em tais níveis que acarreta na liberação de radiação luminosa, porém não se encontram termos químicos como estado fundamental, estado excitado e fóton. 
Quadro 1: Componentes do capítulo 5, tópico 6, do livro Química Cidadã, dos autores Santos e Mól

\begin{tabular}{c} 
Capítulo 5 \\
\hline $6-$ Modelo Atômico de Bohr \\
\hline Introdução \\
\hline Atividade prática \\
\hline Espectros \\
\hline Instrumentos ópticos e onde são usados \\
\hline Teoria de Bohr \\
\hline Exercícios
\end{tabular}

Fonte: Autoria própria (2017).

O livro Química, volume 1, do autor Feltre, 2004, editora Moderna, apresenta no capitulo 4, tópico 5, a transição entre os postulados de Rutherford e Bohr, passando por um breve estudo das ondas e suas características, as ondas eletromagnéticas e seus espectros, a teoria de Bohr definindo quantum e fóton e finaliza o capítulo com atividades práticas, uma revisão, exercícios e exercícios complementares.

Quadro 2: Componentes do capítulo 4, tópico 5, do livro Química, do autor Ricardo Feltre.

\begin{tabular}{c}
\hline Capítulo 4 \\
\hline Introdução \\
\hline Um breve estudo das ondas \\
\hline As ondas eletromagnéticas \\
\hline O modelo de Rutherford-Bohr \\
\hline Atividades práticas \\
\hline Revisão \\
\hline Exercícios \\
\hline Exercícios complementares \\
\hline Fonte: Autoria própria (2017).
\end{tabular}

No livro didático Química, volume 1, da autora Martha Reis, 2013, editora Ártica, é abordado o modelo atômico de Bohr de forma sucinta, no capítulo 11, tópico 5, onde apresentou uma breve introdução de como Bohr chegou a suas teorias, passando pela emissão de radiação, até chegar ao seu estado de elétron, que pode ser definido com fundamental ou excitado. Um ponto positivo é a utilização de termos mais técnicos, que são vistos em testes como o Exame Nacional do Ensino Médio (ENEM) e vestibulares.

Quadro 3: Componentes do capítulo 11, tópico 5, do livro Química, da autora Martha Reis.

\begin{tabular}{c} 
Capítulo 11 \\
\hline $5-$ O Modelo Atômico de Bohr \\
\hline Introdução \\
\hline Órbitas e níveis de energia \\
\hline Definições a partir do elétron de hidrogênio \\
\hline Estado dos elétrons \\
\hline Absorção e liberação de fóton \\
\hline Exercícios
\end{tabular}


Com base nas análises feitas, pode-se perceber algumas distinções entre os livros.

No livro de Santos e Mól, há uma linguagem totalmente didática, criando possibilidade para que o conteúdo chegue de forma mais inteligível para o aluno. É um livro mais lúdico, colorido, com figuras exemplificativas, porém, há a inclusão da parte de espectros dentro do tópico de Bohr, ao invés de ser um tópico separado. É possível perceber também, que não se utilizam termos como estado fundamental, estado excitado e fóton, que são substituídos por outros. Fóton, por exemplo, aparece como radiação luminosa. Após a pesquisa junto a alguns colégios da rede pública, pode-se observar que este livro é muito bem aceito pelos professores do município de Campo Mourão, sendo o livro em vigor em dois dos maiores colégios da cidade.

Já no livro de Feltre, existe uma linguagem mais técnica, não tão clara como a de Santos e Mól, entretanto, sua teoria é a mais completa, contém atividade prática e uma grande quantidade de exercícios, que fazem o aluno refletir sobre a matéria estudada, aumentando seu senso crítico e a relação com seu dia-a-dia.

Em contrapartida, o livro de Reis é contextualizado quando se trata dos conteúdos gerais, com imagens e curiosidades, mas a matéria do modelo atômico de Bohr não é muito aprofundada, possuindo apenas um pouco mais de uma página de conteúdo, o que pode causar um distanciamento em relação com a vida do aluno e causando-lhe pouco interesse. Dentre os três livros observados, esse foi o único que trouxe os termos químicos que são utilizados em livros acadêmicos, e que é visto com grande frequência em vestibulares e até mesmo no exame nacional do ensino médio.

Depois da comparação feita entre os livros e os regimentos das DCE (PARANÁ, 2008), é que observamos as grandes lacunas deixadas pelos escritores. As Diretrizes Curriculares Educacionais orientam que os livros didáticos devem trazer não só uma linhagem teórica, mas devem abranger várias áreas do conhecimento. A química deve estar relacionada com vários âmbitos, desde a matemática até a filosofia, e trazer a arte que está implícita em cada aspecto da sociedade. É de suma importância que os livros acompanhem o crescimento tecnológico e científico, que alteram e melhoram, ano após ano. Os modelos atômicos podem ser considerados a base do ensino de química. É assunto lecionado no início do primeiro ano, e serve como fomentador dos conteúdos subsequentes. As diretrizes defendem que o estudo do átomo tem grande valor, já que o mesmo apresenta um esclarecimento da estrutura da matéria, mostrando suas aplicações, nos contatos diários da sociedade com a química. Porém, os livros analisados não dão a devida importância para tais modelos.

As Diretrizes Curriculares Educacionais (PARANÁ, 2008), também fazem uma crítica sobre o conteúdo aplicado de forma muito teórica e sem contextualização. As DCE defendem que o professor deve mostrar as aplicações das teorias lecionadas. Todavia, os livros didáticos estudados não apresentam propostas de aplicação, deixando apenas a velha e cansativa teoria.

Sendo assim, foi pensado em modo de complementar e contextualizar o assunto de modelo atômico, que pode ser utilizada para integrar os conceitos químicos em voga na pesquisa com a investigação criminal. Para isso, a quimioluminescência pode auxiliar e fomentar discussões, pois para compreender 
tal conteúdo, é necessário ter um conhecimento prévio sobre o modelo atômico de Bohr, fazendo com que assim, haja uma interação entre alguns conteúdos da matriz básica.

Na tentativa de contextualizar o ensino do modelo atômico de Bohr com o cotidiano do aluno, pode-se fazer uma experiência com luminol, explicando a quimioluminescência a partir da química forense.

A priori pode ser aplicado um questionário, com o intuito de avaliar os conhecimentos prévios dos alunos em relação a química forense e investigação criminal, podendo fazer ligações com discussões provenientes de mídias televisivas, por exemplo.

Posteriori, os conceitos e teorias que introduzem o modelo atômico de Bohr podem ser trabalhadas, passando pelas definições de estado fundamental e estado excitado do elétron. Após explicar a liberação dos fótons, a quimioluminescência pode então, ser alvo de discussão e investigação.

Depois de explanar todas as definições, a prática forense pode ser realizada, onde possibilitará fazer a contextualização do conteúdo, e mostrar a reação química do luminol, conciliando assim a fundamentação teórica com a prática do cotidiano da polícia científica e pericia criminal.

Para a atividade prática, de identificação de manchas de sangue a parir do luminol, serão necessários os seguintes materiais:

1.Materiais:

- Sangue de boi;

- Luminol;

- Peróxido de hidrogênio $\left(\mathrm{H}_{2} \mathrm{O}_{2} 20\right.$ Volumes);

- $\quad 2$ tubos de ensaio (por grupo).

\section{Procedimentos:}

Os alunos serão divididos em grupos para que haja um contato maior com a experiência. $O$ discente colocará sangue de boi no primeiro tubo de ensaio e o luminol junto com o peróxido de hidrogênio no segundo, em seguida irão colocar a mistura do luminol e o peróxido de hidrogênio dentro do tubo de ensaio que contém sangue.

Depois de terminar a experiência, os alunos podem ser questionados a respeito do conteúdo explicado e da prática executada, com o objetivo de analisar seu desempenho após a experimentação.

Para que se possa incorporar ainda mais o educando dentro da temática, pode-se apresentar uma problemática, onde um crime fictício é exposto aos mesmos, e eles podem elaborar uma estratégia de investigação, trazendo algo mais lúdico para o contexto escolar, alimentando também, o conhecimento e raciocínio lógico dos alunos.

Após esta contextualização, espera-se que os discentes transformem os seus olhares sobre a química, e que os mesmos carreguem com sigo o interesse, e principalmente a curiosidade e a criticidade, até o fim de suas vidas acadêmicas. 
universal, que pode fornecer explicações sobre várias esferas do cotidiano, e está incorporada em todo nosso arredor.

\section{CONCLUSÃO}

Ao término da pesquisa foi observado que o modelo atômico de Bohr possui algumas carências nos livros didáticos, pois os mesmos trazem poucas explicações e não propõem contextualizações com o cotidiano do aluno, tornando a matéria demasiadamente abstrata. Pode-se afirmar também, que há pouca interdisciplinaridade com outras matérias, indo na contramão do que propõe as Diretrizes Curriculares da Educação Básica de Química do Estado do Paraná.

Constatou-se que a integração da química forense e da quimioluminescência pode ser uma boa saída para fundamentar a explicação das teorias de Bohr. E experiências como a do luminol em manchas de sangue e a cena fictícia do crime, são exemplos de contextualizações que o docente pode aplicar em sala de aula, a fim de cativar o aluno, e mostrar os lugares da química no mundo. 


\title{
The teaching of the Bohr atomic model, chemiluminescence, and luminol: analysis of the textbooks of Campo Mourão, based on the curricular guidelines of chemistry's basic education of Paraná
}

\begin{abstract}
The article suggests the contextualization of the teaching of Bohr's postulated with everyday social life, using the concept of chemiluminescence as part of forensic chemistry, with the purpose of instigating the interest and the critical sense of the student, showing a practical application of the chemical reaction of luminol. The study was carried out by reading and analyzing three chemistry textbooks of the first year of high school used in the Municipality of Campo Mourão, comparing them with the curricular guidelines of the basic education of chemistry of the state of Paraná. The books "Química Cidadã" by Widson Santos and Gerson Mól, "Química" of Ricardo Feltre and "Química" of Martha Reis were analyzed and they presented some distinctions based on the established criteria. A practical activity was proposed for a better contextualization with the daily life of the students.At the end of the research, it was observed that the Bohr atomic model has some deficiencies in the textbooks analyzed. In addition, because it presents little contextualization, it goes against what the DCE stands for.
\end{abstract}

KEYWORDS: Textbooks. Atomic model. Chemiluminescence. Forensic chemistry. 


\section{AGRADECIMENTOS}

Quando escolhemos ingressar em um curso de licenciatura estávamos cientes dos desafios que viriam pela frente, passamos por muitas dificuldades para chegar até aqui. Agora estamos no primeiro semestre do curso de licenciatura em química, orgulhosos pela escolha e por todo percurso que tivemos que fazer. Sabemos que a caminhada ainda será árdua e longa, mas não tememos o que vem pela frente, pois sabemos que junto com os problemas virão pessoas incríveis, como a pessoa que é a grande motivadora deste trabalho. Dedicamos e agradecemos por esse este projeto a professora Bruna Adriane Fary, pelo incentivo e principalmente por acreditar em nós, a cada aula que temos com ela, vem junto a reafirmação de que estamos no caminho e no curso certo, e esperamos um dia nos tornarmos grandes educadores, assim como a mesma.

\section{REFERÊNCIAS}

ALMEIDA, E. C. S. et al. Contextualização do ensino de química: motivando alunos de ensino médio. X Encontro de Extensão, UFPB, 2007.

BRASIL. Secretaria da Educação Básica. Ministério da Educação. Orientações Curriculares Para o Ensino Médio: Ciências da Natureza, Matemática e suas Tecnologias. Brasília: MEC, 2006.

BRASIL. Secretaria de Estado de Educação do Paraná. Diretrizes Curriculares de Educação Básica: Química. Paraná, 2008.

BRASIL. Secretaria de Educação Média e Tecnológica. Ministério da Educação e Cultura. Parâmetros Curriculares Nacionais para o Ensino Médio: Ciências da Natureza, Matemática e suas Tecnologias. Brasília: MEC/SEMTEC, v. 3, 1999.

CASTRO, M. A.; JUNIOR, A. S. R. Das Provas Periciais no Processo Penal Brasileiro. Diálogos \& Saberes, Mandaguari, v. 9, n. 1, p. 181-196, 2013. Disponível em: <http://seer.fafiman.br/index.php/dialogosesaberes/article/viewFile/332/323> Acesso em: 11 mai. 2017.

FARIAS, R. F. Introdução a Química Forense. São Paulo: Editora Átomo, 2a ed., 2008.

FELTRE, R. Química: Química Geral. São Paulo: Editora Moderna, 6a ed., v.1, 2004.

FERREIRA, E. C.; ROSSI, A. V. A Quimioluminescência Como Ferramenta Analítica: 
<http://www.scielo.br/scielo.php?script=sci_arttext\&pid=S0100-

40422002000600018>. Acesso em: 10 mai. 2017.

GROTTO, H. Z. W. Metabolismo do Ferro: Uma Revisão Sobre os Principais Mecanismos Envolvidos mm Sua Homeostase. Revista Brasileira de Hematologia e Hemoterapia, 2008. Disponível em:

$<$ http://www.scielo.br/pdf/rbhh/v30n5/v30n5a12.pdf>. Acesso em: 08 mai. de 2017.

KOTZ, J. C. et al. Química Geral e Reações Químicas. São Paulo: Editora CengageLaerning, 6a ed., v.1, p.265-269, 2009.

MÓL, G.; SANTOS, W.. Química Cidadã. São Paulo: Editora AJS, 2ª ed., v.1, 2013.

MOTA, L.; DI VITTA, P. B. Química Forense: Utilizando Métodos Analíticos Em Favor do Poder Judiciário. Revista Oswaldo Cruz, 2012. Disponível em: <http://www.revista.oswaldocruz.br/Content/pdf/Qu\%C3\%ADmica_Forense_utili zando_m\%C3\%A9todos_anal\%C3\%ADticos_em_favor_do_poder_judici\%C3\%A1ri o_.pdf>. Acesso em: 11 mai. 2017.

NERY, A. L. P.; BAADER, W. J. Quimiluminescência de Peróxidos Orgânicos: Geração de Estados Eletronicamente Excitados na Decomposição de 1,2Dioxetanos. Química Nova, 2001. Disponível em: $<$ http://www.scielo.br/scielo.php?script=sci_arttext\&pid=S010040422001000500010\&lng=pt\&nrm=iso\&tlng=pt>. Acesso em: 10 mai. 2017.

PARANÁ. Diretrizes Curriculares da Educação Básica de Química. 2008. Disponível em: <http://www.quimica.seed.pr.gov.br/arquivos/File/pdf/dce_quim.pdf>. Acesso em: 08 abr. 2017.

PILETTI, C. Didática Geral. 23ạ ed., São Paulo: Ática, 2004.

QUÍMICA GERAL. Departamento de Química, UFMG. Disponível em: <http://zeus.qui.ufmg.br/ qgeral/?cat=8\&paged=2>. Acesso em: 22 jun. 2017.

REIS, M. Química. São Paulo: Ártica, 1a ed., v.1, 2013.

VIDOTTO, A.; QUEIROZ, P. R. Técnica de quimioluminescência em manchas de sangue: o uso de luminol para a sua identificação. Pontifícia Universidade 
<http://www.cpgls.pucgoias.edu.br/6mostra/artigos/SAUDE/ANANZA\%20VIDOTT O\%20E\%20\%20PAULO\%20ROBERTO\%20QUEIROZ.pdf>. Acesso em: 09 mai. 2017.

WELSH, E. What is Chemiluminescence? Science in School, England, 2011. Disponível em:

<http://www.scienceinschool.org/2011/issue19/chemiluminescence>. Acesso em: 08 mai. 2017.

ZANON, L.B. e PALHARINI, E.M. A química no ensino fundamental de ciências. Química Nova na Escola, n. 2, p.15-18, 1995.

Recebido: 30 jul. 2017

Aprovado: 18 dez. 2017.

DOI: $10.3895 /$ actio.v3n1.6841

Como citar:

OLIVEIRA JUNIOR, A. S. FARY, B. A. PEREIRA, L. G. S. O. RODRIGUES, M. V. O. Ensino do modelo atômico de Bohr, quimioluminescência e luminol: análise dos livros didáticos de Campo Mourão com base nas diretrizes curriculares da educação básica de química do Paraná. ACTı, Curitiba, v. 3, n. 1, p. 75-90, jan./abr. 2018. Disponível em: <https://periodicos.utfpr.edu.br/actio>. Acesso em: XXX.

Correspondência:

Adil de Souza Oliveira Junior

Rua Itamaraty, n. 47, 87318-000, Piquirivaí, Campo Mourão, Paraná, Brasil

Direito autoral: Este artigo está licenciado sob os termos da Licença Creative Commons-Atribuição 4.0

Internacional. 